Case Report

\title{
The Use of Adenosine to Enable Safe Implantation of Transcatheter Tricuspid Valve
}

\author{
Vicki Zeniou, Shmuel Chen, Mony Shuvy, David Luria, Chaim Lotan, and \\ Haim D. Danenberg
}

Hadassah Hebrew University Medical Center, Jerusalem, Israel

Correspondence should be addressed to Vicki Zeniou; vickizenios@hotmail.com

Received 30 July 2017; Accepted 14 September 2017; Published 16 November 2017

Academic Editor: Assad Movahed

Copyright (C) 2017 Vicki Zeniou et al. This is an open access article distributed under the Creative Commons Attribution License, which permits unrestricted use, distribution, and reproduction in any medium, provided the original work is properly cited.

\begin{abstract}
High precision is necessary during percutaneous transcatheter heart valve implantation. The precision of the implantation has been established by increasing the heart rate (usually to 200 beats per minute) to the point of significantly reduced cardiac output and thus minimizing valve movement. Routinely, this tachycardia is induced by rapid pacing. Here we report a case of failure to pace during valve-in-valve (VIV) Edwards Sapien XT implantation in the tricuspid valve position. Transient cardiac arrest was induced by intravenous adenosine injection enabling accurate valve implantation.
\end{abstract}

\section{Introduction}

Transcatheter valve-in-valve (VIV) procedures are relatively new procedures performed increasingly in degenerative bioprosthetic valves as an alternative to surgical replacement. The procedure has challenging technical aspects and requires high level of accuracy. During valve implantation, accuracy is achieved by rapid pacing, which reduces cardiac output and minimizes involuntary valve movement. For this reason, a temporary electrode is placed in the right ventricle.

For tricuspid VIV procedures, pacing may be induced by an electrode placed either in the left ventricle or in the coronary sinus. An attempt may also be made to deploy the valve without pacing due to the low flow velocity in the right ventricle outflow tract.

This is a case of failed rapid pacing during tricuspid VIV implantation. Adenosine was used as an alternative to create temporary heart block, enabling accurate valve deployment during the cardiac arrest period. Adenosine inhibits atrioventricular (AV) node conduction, leading to a short-acting AV block and temporary cardiac asystole [1].

\section{Case Report}

A 63-year-old female with a medical history of rheumatic heart disease, ischemic heart disease, chronic atrial fibrillation, past stroke, and cerebral palsy, who underwent mechanical mitral valve replacement and biological tricuspid valve replacement (Edwards Lifesciences, Perimount $29 \mathrm{~mm}$ ) at the age of 55, was currently admitted with shortness of breath and severe pitting leg edema. Echocardiography revealed moderate aortic stenosis (mean gradient $30 \mathrm{mmHg}$ ), good function of the mechanical mitral valve, severe (free) tricuspid valve regurgitation, and significant tricuspid valve stenosis (Figures 1(a) and 1(b)). The maximal velocity through the tricuspid valve was measured to be $2.06 \mathrm{~m} / \mathrm{s}$ with a calculated maximal pressure gradient of $17 \mathrm{mmHg}$ and a mean pressure gradient of $11 \mathrm{mmHg}$. A right heart catheterization that was performed verified these measurements. STS score for mortality was $9 \%$, and the patient was considered by the heart team to be extremely high risk for surgery. The patient was thus referred for percutaneous transfemoral tricuspid VIV implantation under conscious sedation. Due to normal right-ventricular contraction and high systolic pressures, it was decided to perform the 


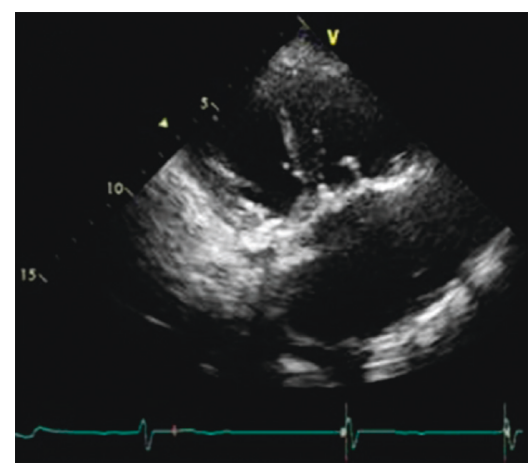

(a)

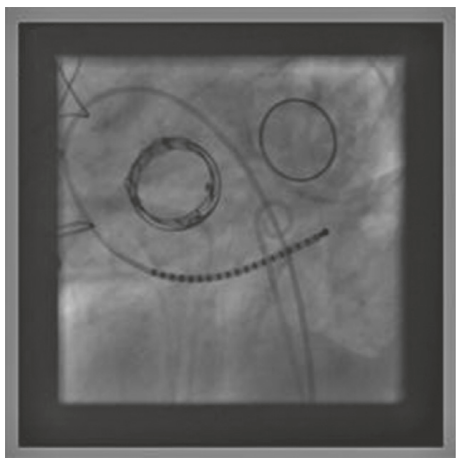

(d)

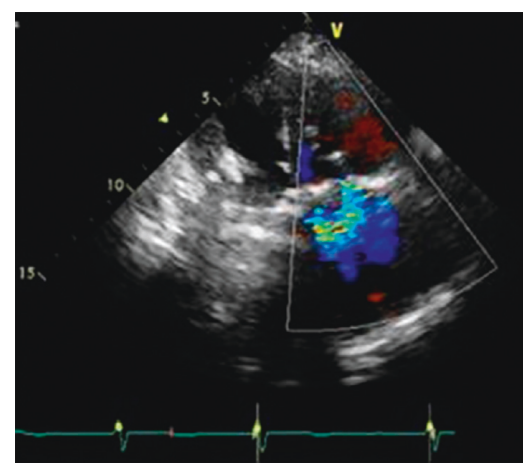

(b)

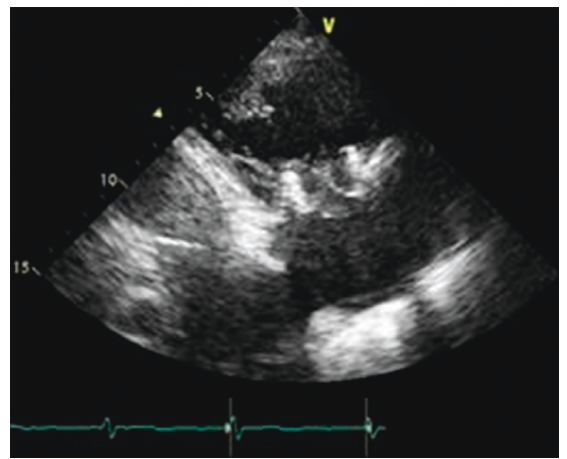

(e)

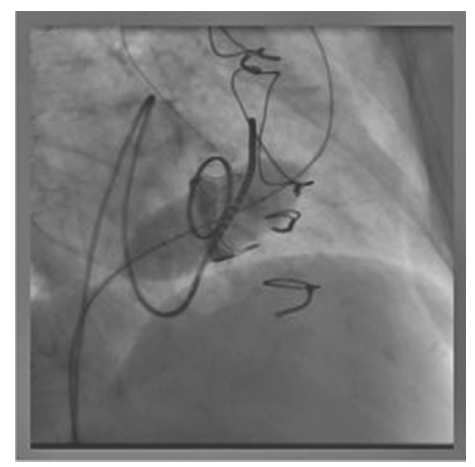

(c)

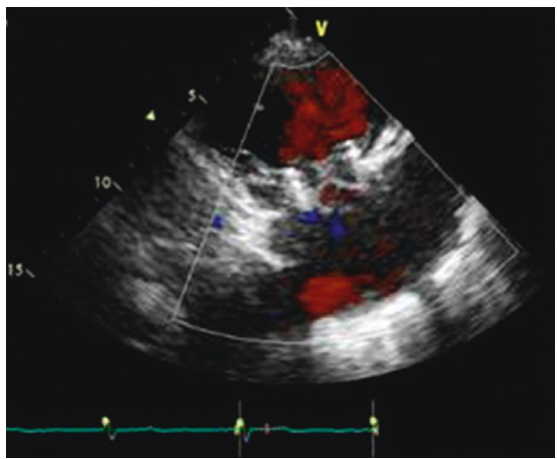

(f)

Figure 1

procedure with rapid pacing. Several options for placement of the electrode were considered. Insertion of a rightventricular electrode is associated with the risk of it being jailed between the old and new prostheses. Furthermore, insertion of a left-ventricular electrode is technically difficult due to the presence of aortic stenosis. In addition, rapid right-atrial pacing did not allow for proper capture of the ventricle. It was decided to place a temporary electrode in the coronary sinus for rapid pacing, but again rapid ventricular pacing could not be achieved due to technical difficulties. Therefore, cardiac arrest was attempted with $6 \mathrm{mg}$ of adenosine; however, this dose was not adequate, and thereafter cardiac arrest was induced with bolus injection of $18 \mathrm{mg}$ of adenosine through a peripheral vein access. Asystole was induced, and a balloon expandable valve (Edwards Lifesciences, Sapien XT $29 \mathrm{~mm}$ ) was deployed in the tricuspid valve bioprosthesis (Figures 1(c) and 1(d)). Asystole lasted for nine seconds, allowing slow and accurate balloon inflation and valve deployment. Asystole was followed by slow resumption of cardiac rhythm at a heart rate of $60 \mathrm{bpm}$. Recovery was immediate, postprocedural course was uneventful, and echocardiography demonstrated normal left- and right-ventricular function, with no significant tricuspid valve stenosis (mean $5 \mathrm{mmHg}$ ) and mild tricuspid paravalvular regurgitation (Figures 1(e) and 1(f)). Echocardiographic follow-up of the patient a year after the procedure showed good global systolic function, with mild paravalvular leak of the tricuspid valve. Heart movement during the cardiac cycle can impact the accuracy of valve implantation, resulting in possible displacement and subsequently increasing the rate of complications.

\section{Discussion}

Cardiac movement might influence the height of implantation in relation to the aortic annulus and increase the probability of paravalvular leak and atrioventricular conduction disturbances, which, in turn, may negatively influence the prognosis of the patient. These movements mainly have an effect on balloon expandable valves, and therefore rapid pacing is considered mandatory during such procedures. Adenosine administered intravenously can induce transient cardiac arrest by inhibiting AV nodal conduction. Having a half-life from 10 to 30 seconds, its effect is achieved rapidly after injection (10-15 seconds) and lasts for several seconds (the drug is cleared from the plasma within 30 seconds). Thus, it has suitable pharmacological features for potential use to induce heart arrest during percutaneous cardiac interventions. The adverse effects are self-limiting, and during the procedure there was no case of bronchospasm.

The literature reveals adenosine being successfully used to enhance accurate deployment of stent grafts in the thoracic aorta $[2,3]$ and in the implantation of an ostial coronary stent [4]. Davidavicius et al. performed a prospective pilot study and found the use of adenosine safe and feasible to 
achieve cardiac arrest in 20 patients who underwent TAVI with balloon valvuloplasty in whom rapid pacing would be not well tolerated [5]. Furthermore, it has been reported that adenosine has been used in extracardiac procedures. Pile-Spellman et al. used a rapid injection of $64 \mathrm{mg}$ of adenosine to induce rapid reversible high atrioventricular block and hypotension in order to effectively and safely deposit glue in cerebral arteriovenous malformations during microsurgical resection [6]. After this, Groff et al. published a case in which $6 \mathrm{mg}$ in addition to another $12 \mathrm{mg}$ of adenosine was administered through a central venous catheter to induce hypotension and collapse of the aneurysm in an arteriovenous malformation allowing for closure with a clip [7]. To our knowledge, the current report is the first description of adenosine-induced temporary heart block during percutaneous valve implantation. As it was described above, adenosine could safely enable valve deployment during the tricuspid VIV procedure during which other techniques of reducing cardiac output were unavailable or difficult to pursue.

\section{Conflicts of Interest}

The authors declare that there are no conflicts of interest regarding the publication of this article.

\section{Authors' Contributions}

Vicki Zeniou and Shmuel Chen equally contributed to this work.

\section{References}

[1] L. Belardinelli, J. Linden, and R. M. Berne, "The cardiac effects of adenosine," Progress in Cardiovascular Diseases, vol. 32, no. 1, pp. 73-97, 1989.

[2] T. D. Fang, M. Lippmann, C. Kakazu et al., "High-dose adenosine-induced asystole assisting accurate deployment of thoracic stent grafts in conscious patients," Annals of Vascular Surgery, vol. 22, no. 5, pp. 602-607, 2008.

[3] R. A. Kahn, D. M. Moskowitz, M. L. Marin et al., "Safety and efficacy of high-dose adenosine-induced asystole during endovascular AAA repair," Journal of Endovascular Therapy, vol. 7, no. 4, pp. 292-296, 2000.

[4] D. Dvir, S. Badr, and A. D. Pichard, "Adenosine-induced temporary block to improve accuracy of ostial coronary stent implantation: adenosine to improve stent implantation accuracy," Catheterization and Cardiovascular Interventions, vol. 83, no. 1, pp. E61-E63, 2014.

[5] G. Davidavicius, A. Chieffo, J. Shannon et al., "A high dose of adenosine to induce transient asystole for valvuloplasty in patients undergoing transcatheter aortic valve implantation (TAVI): is it a valid alternative to rapid pacing? A prospective pilot study," Journal of Invasive Cardiology, vol. 23, no. 11, pp. 467-471, 2011.

[6] J. Pile-Spellman, W. L. Young, S. Joshi et al., "Adenosineinduced cardiac pause for endovascular embolization of cerebral arteriovenous malformations: technical case report," Neurosurgery, vol. 44, no. 4, pp. 881-886, 1999.

[7] M. W. Groff, D. C. Adams, R. A. Kahn, U. M. Kumbar, B. Y. Yang, and J. B. Bederson, "Adenosine-induced transient asystole for management of a basilar artery aneurysm. Case report," Journal of Neurosurgery, vol. 91, no. 4, pp. 687-690, 1999. 


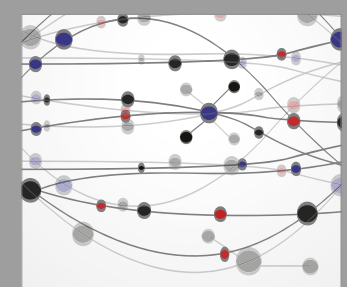

The Scientific World Journal
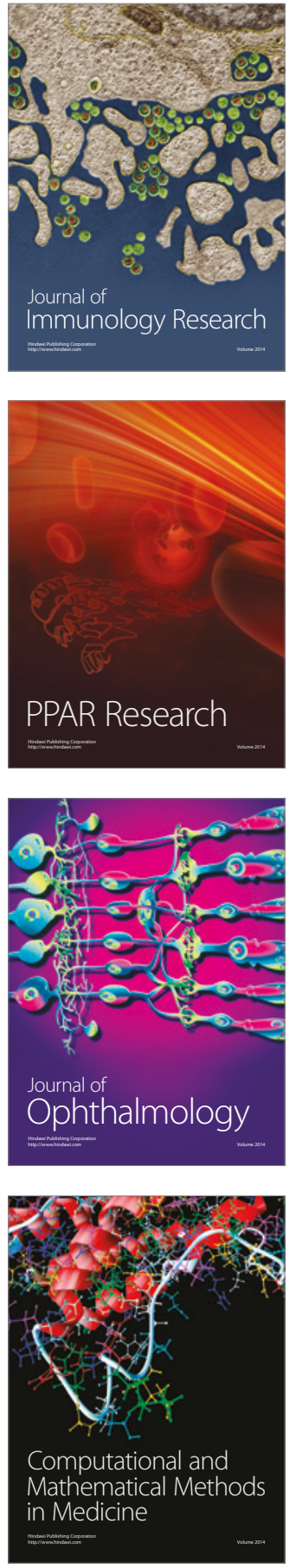

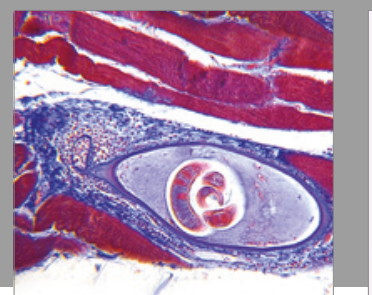

Gastroenterology Research and Practice
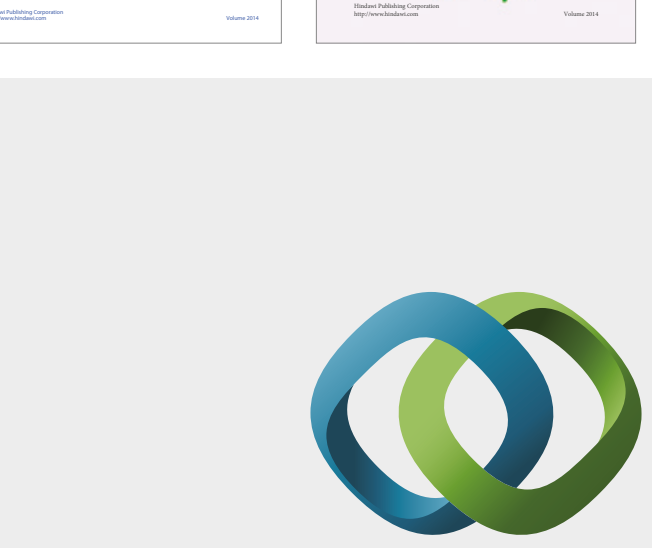

\section{Hindawi}

Submit your manuscripts at

https://www.hindawi.com
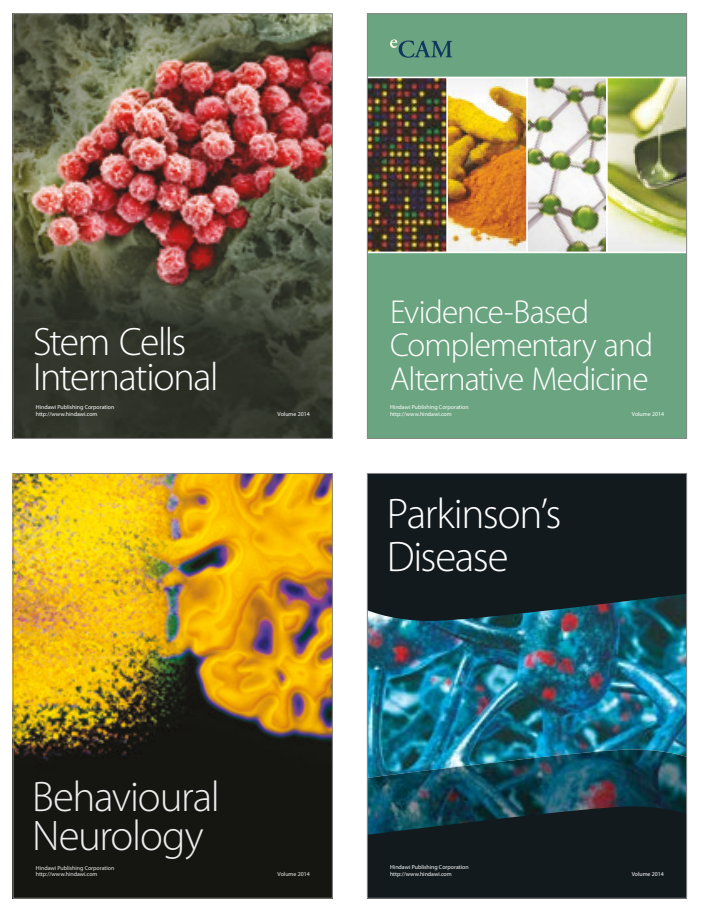
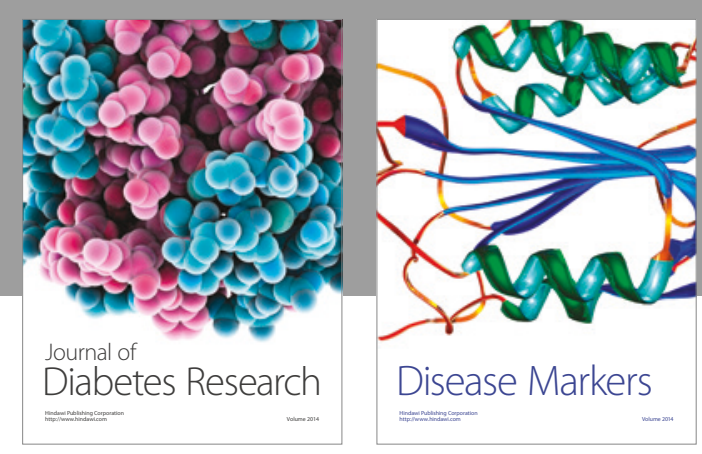

Disease Markers
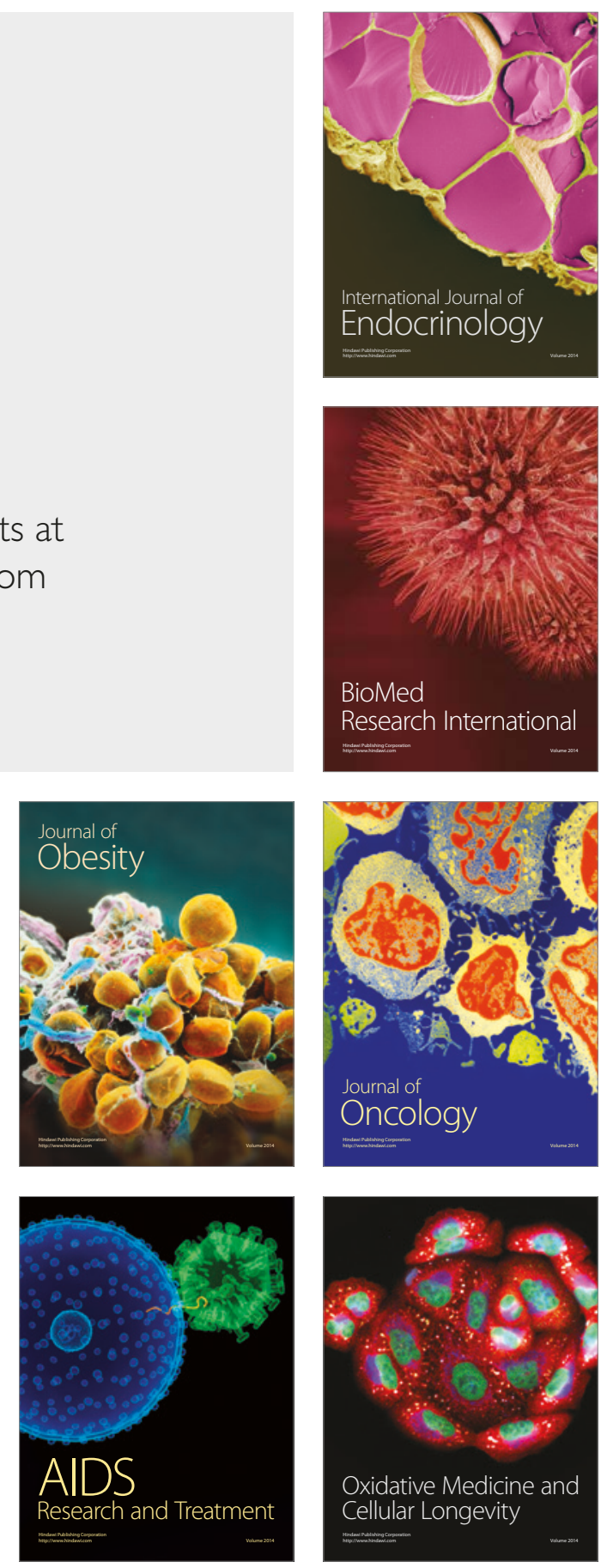